\title{
Editorial on: current state of empyema management
}

\author{
Martin Reichert ${ }^{1}$, Johannes Bodner ${ }^{2,3}$ \\ ${ }^{1}$ Department of General, Visceral, Thoracic, Transplant and Pediatric Surgery, University Hospital of Giessen, Giessen, Germany; ${ }^{2}$ Department \\ of Thoracic Surgery, Klinikum Bogenhausen, Munich, Germany; ${ }^{3}$ Department of Visceral, Transplant and Thoracic Surgery, Center of Operative \\ Medicine, Innsbruck Medical University, Innsbruck, Austria \\ Correspondence to: Johannes Bodner. Department of Thoracic Surgery, Klinikum Bogenhausen, Englschalkinger Strasse 77, 81925 Munich, Germany. \\ Email: Johannes.Bodner@klinikum-muenchen.de. \\ Provenance: This is an invited Editorial commissioned by the Section Editor Laura Chiara Guglielmetti (Cantonal Hospital Winterthur, Kantonsspital \\ Winterthur, Winterthur, Switzerland). \\ Comment on: Semenkovich TR, Olsen MA, Puri V, et al. Current state of empyema management. Ann Thorac Surg 2018;105:1589-96.
}

Submitted Sep 06, 2018. Accepted for publication Sep 25, 2018.

doi: $10.21037 /$ jtd.2018.10.46

View this article at: http://dx.doi.org/10.21037/jtd.2018.10.46

Semenkovich and colleagues report in their article "Current state of empyema management" on the up-to-date practice of empyema management based on retrospectively analyzed patient cohort (from 2009 to 2014) within the statewide comprehensive, longitudinal maintained New York Inpatient Database (1). They focused on patients hospitalized for inpatient treatment of primary pleural empyema and stratified these patients based on their definitive intervention into three cohorts: (I) patients received only medical therapy with chest tube drainage or surgical therapy with (II) video-assisted thoracoscopic surgery (VATS) or (III) conventional open surgery (COS) (1). They totally screened 11,205 discharges for pleural empyema in 9,797 patients and finally included 4,095 patients matching the inclusion criteria. The excluded patients were either not residents in New York-resulting in a lack of follow-up data and incomplete longitudinal documentation within the database-and/or were suspected for secondary pleural empyema (1).

The key findings of the study by Semenkovich and colleagues were (1):

(I) Patient characteristics: those patients only receiving chest tube placement were older, had more comorbidities and had severer systemic reactions (higher rate of shock and septicemia);

(II) Initial treatment: also, among the others, most patients were initially managed by chest tube placement (overall 67.8\%), whereas the success rate of a complete conservative/nonsurgical treatment during the index hospitalization was low (56\%);

(III) Definitive treatment: the primary treatment success rate (defined by 30-day survival and 30-day reintervention for pleural empyema) after one single invasive procedure during the index hospitalization was lowest $(37 \%)$ after chest tube placement compared to surgically treated patients $(55 \%$ and $58 \%$ after VATS and COS, respectively);

(IV) Outcome: length of index hospital stay was longest for patients after COS and shortest after VATS (with length of hospital stay after chest tube placement in between). Length of hospital stay was longer in patients who required multiple procedures for managing pleural empyema compared to singleprocedure treatment (median 15 vs. 12 days). Reintervention and re-admission rates were highest in patients primarily managed by chest tube drainage (> COS > VATS) at 30 and 90 days, respectively. The same holds true for mortality rate of these patients during the index hospitalization, at 30 and 90 days (chest tube treatment $>$ COS $>$ VATS).

(V) Longitudinal state of empyema management: during the study period most patients were definitively managed by any type of surgery (VATS or COS) within the index hospitalization $(62 \%)$. Interestingly, there was a trend $(\mathrm{P}=0.07)$ to increasing rate of VATS-procedures and 


\begin{tabular}{|c|c|c|c|c|c|}
\hline Simple & \multicolumn{2}{|c|}{ Complicated pleural effusion (4-6) } & Empyema thoracis & $\rightarrow \mathrm{Pr}$ & ogressive disease \\
\hline ATS (3) & \multicolumn{2}{|c|}{$\begin{array}{l}\text { Exudative phase (stage I) } \\
\text { - Inflammatory processes extend } \\
\text { to the pleurae and result in } \\
\text { immediate outpouring fluid; } \\
\text { - Low cell content; } \\
\text { - Re-expandable lung. }\end{array}$} & $\begin{array}{l}\text { Fibropurulent phase (stage II) } \\
\text { - } \quad \text { Frank pus accumulates especially } \\
\text { laterally and dorsally; } \\
\text { - High cell content (PMN) and fibrin } \\
\text { depositions over the pleural surfaces } \\
\text { and fibrinous strands within the fluid; } \\
\text { - Tendency to loculations and } \\
\text { - } \text { formations of membranes; } \\
\text { - Beginning constriction of the lung. }\end{array}$ & $\begin{array}{ll}\text { Org } \\
\bullet & \\
- & 1 \\
-1 & 1 \\
-1\end{array}$ & $\begin{array}{l}\text { anized phase (stage III) } \\
\text { Thick and sedimented exudate; } \\
\text {-ibroblast growth; } \\
\text { ibrosis; } \\
\text { nelastic membranes over the } \\
\text { leural surfaces; } \\
\text { rapped lung. }\end{array}$ \\
\hline \multirow[t]{3}{*}{ Therapy } & \multicolumn{5}{|c|}{ Antibiotics } \\
\hline & \multirow{2}{*}{$\begin{array}{l}\text { Thoracocentesis } \\
\text { (repeated) }\end{array}$} & \multirow{2}{*}{$\begin{array}{l}\text { Chest tube } \\
\text { drainage }\end{array}$} & \multicolumn{3}{|c|}{ VATS for evacuation of pus and loculations and decortication or } \\
\hline & & & $\begin{array}{l}\text { Chest tube drainage + intrapleural fibrino } \\
\text { agents }\end{array}$ & & $\begin{array}{l}\text { Open decortication, open window } \\
\text { thoracostomy, thoracomyoplasty } \\
\text { (depending on etiology) }\end{array}$ \\
\hline
\end{tabular}

Figure 1 ATS-phase directed therapy of parainfectious/parapneumonic pleural fluid collections an pleural empyema [modified from Reichert et al. and Andrews et al. (2,3)]. The earlier phase of pleural empyema merges into the next, more complicated one when therapy is insufficient. The primary goals of pleural empyema treatment are: infectious focus control and re-expansion of the lung. This is achieved in accordance to the phase of the empyema by chest tube and/or surgical drainage (4-6). ATS, American Thoracic Society; PMN, polymorph nuclear neutrophils; VATS, video-assisted thoracoscopic surgery.

decreasing rate of open surgical approaches during the study period from 2009 to 2014. Furthermore, the authors evaluated a higher rate of the VATSapproach compared to COS in larger ( $>300$ beds) compared to smaller hospitals.

The clinical treatment of pleural empyema is complex and should always be multidisciplinary (2). The evidence for pleural empyema treatment is mainly based on small retrospective case series, including heterogenous cohorts of patients with different phases of pleural empyema (2). The results from Semenkovich and colleagues reflect the current knowledge of the disease and best evidence practice for pleural empyema treatment. Semenkovich et al. thereby include all-nonoperatively as well as surgically treated-patients into their study and do not differentiate between the different empyema phases. They thus provide a "global" view on the current state of pleural empyema treatment or rather specifically on specific limitations of pleural empyema treatment modalities (1). Most patients $(67.8 \%)$ in this database study were initially treated by chest tube insertion, assumingly as an effort to early control the septic focus and as an initial trial for conservative treatment; however, almost the half of these patients required surgery thereafter, indicating an insufficient initial therapy $(1,2)$. In pleural empyema, the appropriate therapeutic approach should be considered in accordance to the phase otherwise therapy will not be sufficient and the disease merges from an earlier, uncomplicated phase into the next and more complicated one (2). Pleural empyema was graduated-from the surgeons' point of view-most relevantly (and simple) by the American Thoracic Society already in 1962 into three phases: the early exudative phase, the intermediate fibropurulent phase and the late organized phase (2,3) (Figure 1). Primary goals in the treatment of pleural empyema are infectious source control and removal of pleural fluid collections in phase 1 , additional debridement of the pleural cavity in phase 2 and decortication of the lung, mediastinum and chest wall in order to allow the lung to re-expand in phase 3 (2). This can be achieved by chest tube drainage in phase 1 , by surgical drainage with pleural debridement of fibrinous septae in phase 2 and surgical decortication in phase 3 (Figure 1) $(2,7)$. Unfortunately, as the authors themselves discuss as a limitation of their study, neither a graduation of the study cohort into the different phases of the pleural empyema nor a retrospective evaluation of the particular treatment considerations and intentions for or against the type of initial drainage were deducible from the database; just as little as more detailed information about further treatment modalities (e.g., usage of fibrinolytic 
agents via thoracic drains, open window thoracostomy or thoracomyoplasty) (1). Thus, it remains unclear if the chest tube placement as an initial procedure in $67.8 \%$ of the patients was seen and chosen as the appropriate therapeutic trial according to the clinical phase of the disease; or, if the patients' acute critical state did not allow for primary surgical intervention meaning that the chest tube was thus chosen for initial infectious source control and as a bridge to definitive surgical drainage (or as a definitive treatment measure in patients, who were too acutely or chronically ill for any major surgical intervention) (1). However, about $50 \%$ of these patients underwent treatment conversion to any type of surgery. A mean finding of the study by Semenkovich et al. is, that only $53 \%$ of the patients at all were treated with a single procedure, but the length of hospital stay was significantly reduced if first treatment was successful. This led to the authors' conclusion that patients, who are appropriate candidates for surgical therapy, should be early identified and that a timely provision of the definitive therapy improves outcome of the patients (1). Interestingly, patients managed with only chest tube drainage were older, had more serious systemic comorbidities and a higher rate of acute illness (e.g., shock and septicemia) (1). Primary pleural empyema is a severe infectious disease with a high morbidity and reported mortality rates range between $10-27 \%$ or even higher if therapy is insufficient (2). The overall health condition of affected patients (e.g., chronic comorbidities, acute shock and septicemia) but also ineffective treatment (e.g., chest tube drainage) may lead to highest rates of treatment conversion, re-admission, re-interventions and mortality (1).

Interestingly but somehow still as expected Semenkovich et al. found a switch from more open (COS) procedures at the beginning to an increase of the minimally-invasive VATS-approach over the study period, especially in larger hospitals (1). Though usually no hilar or lobar vascular and bronchial structures are dissected, decortication of the lung in (chronic) phase III empyema is nevertheless a technical challenging procedure requiring a lot of experience in VATS. The learning curve of about 40 cases is rather flat (8) and similar to that of minimally-invasive anatomic lung resections (9). However, in specific thoracic, high volume departments dedicated surgeons have increasingly developed and adopted this technique $(8,9)$ thereby bestowing also patients with septic pleural disease on the well-known advantages of the minimally-invasive approach $(2,8,10)$. In fact, Semenkovich et al. found the length of hospital stay as well as the re-intervention-, re-admission- and mortality- rates to be lowest in VATS patients when compared to those who underwent COS or chest tube drainage only (1). Despite of the rather low level of evidence and the lack of prospective randomized studies $(7,11-14)$ the European Association for Cardio-Thoracic Surgery (EACTS) recommends a primary VATS-approach with a conversion to COS only if necessary for surgery of pleural empyema even in the organized phase 3 (7), it would have been interesting if the authors had itemized the surgical approach rates according to the different empyema stages.

In conclusion, Semenkovich and colleagues are to be congratulated and thanked for comparing and proofing current-surgical and nonsurgical-invasive treatment options in pleural empyema. The results of the study support the importance of an early and sufficient drainage therapy. Some type of surgical drainage therapy-by VATS or COS-is indicated in the very most patients suffering from pleural empyema in order to achieve complete disease control and to avoid high rates of morbidity and mortality.

\section{Acknowledgements}

None.

\section{Footnote}

Conflicts of Interest: The authors have no conflicts of interest to declare.

\section{References}

1. Semenkovich TR, Olsen MA, Puri V, et al. Current State of Empyema Management. Ann Thorac Surg 2018;105:1589-96.

2. Reichert M, Hecker M, Witte B, et al. Stage-directed therapy of pleural empyema. Langenbecks Arch Surg 2017;402:15-26.

3. Andrews NC, Parker EF, Shaw RR, et al. Management of non tuberculous empyema: a statement of the subcommittee on surgery. Am Rev Respir Dis 1962;85:935.

4. Davies CW, Gleeson FV, Davies RJ. BTS guidelines for the management of pleural infection. Thorax 2003;58 Suppl 2:ii18-28.

5. Light RW. A new classification of parapneumonic effusions and empyema. Chest 1995;108:299-301.

6. Muers MF. Streptokinase for empyema. Lancet 1997;349:1491-2.

7. Scarci M, Abah U, Solli P, et al. EACTS expert consensus 
statement for surgical management of pleural empyema. Eur J Cardiothorac Surg 2015;48:642-53.

8. Reichert M, Pösentrup B, Hecker A, et al. Lung decortication in phase III pleural empyema by videoassisted thoracoscopic surgery (VATS) — results of a learning curve study. J Thorac Dis 2018;10:4311-20.

9. Reichert M, Gohlke AB, Augustin F, et al. Videoassisted thoracoscopic anatomic lung resections in Germany-a nationwide survey. Langenbecks Arch Surg 2016;401:877-84.

10. Reichert M, Kerber S, Posentrup B, et al. Anatomic lung resections for benign pulmonary diseases by video-assisted thoracoscopic surgery (VATS). Langenbecks Arch Surg 2016;401:867-75.

Cite this article as: Reichert M, Bodner J. Editorial on: current state of empyema management. J Thorac Dis 2018;10(Suppl 33):S4043-S4046. doi: 10.21037/jtd.2018.10.46
11. Drain AJ, Ferguson JI, Sayeed R, et al. Definitive management of advanced empyema by two-window video-assisted surgery. Asian Cardiovasc Thorac Ann 2007;15:238-9.

12. Waller DA, Rengarajan A. Thoracoscopic decortication: a role for video-assisted surgery in chronic postpneumonic pleural empyema. Ann Thorac Surg 2001;71:1813-6.

13. Chung JH, Lee SH, Kim KT, et al. Optimal timing of thoracoscopic drainage and decortication for empyema. Ann Thorac Surg 2014;97:224-9.

14. Reichert M, Posentrup B, Hecker A, et al. Thoracotomy versus video-assisted thoracoscopic surgery (VATS) in stage III empyema-an analysis of 217 consecutive patients. Surg Endosc 2018;32:2664-75. 